\title{
GAIA Level 3 Non-reassuring Fetal Status
}

National Cancer Institute

\section{Source}

National Cancer Institute. GAlA Level 3 Non-reassuring Fetal Status. NCI Thesaurus. Code C127996.

GAIA Level 3 Non-reassuring Fetal Status is defined by the presence of the following criteria: A fetal heart pattern that is detected via intermittent auscultation, and that is suggestive of fetal hypoxia, including the following requirements that must be met: a) Baseline fetal heart rate less than 110 bpm or greater than 160 bpm; b) Presence of repetitive or prolonged (greater than 3 minutes) decelerations; c) More than five contractions in a ten minute period. 